\title{
Long-term clinical effects of interferon gamma-1b and colchicine in idiopathic pulmonary fibrosis
}

\author{
K.M. Antoniou*, A.G. Nicholson\#, M. Dimadi ${ }^{\#,}$, K. Malagari ${ }^{+}$, P. Latsi ${ }^{\S}$, A. Rapti ${ }^{\mp}$, \\ N. Tzanakis*, R. Trigidou ${ }^{f}$, V. Polychronopoulos** and D. Bouros ${ }^{\# \#}$
}

ABSTRACT: Idiopathic pulmonary fibrosis (IPF)/usual interstitial pneumonia is a deadly disease with no effective treatment. The purpose of this randomised prospective multicentric study was to characterise the clinical effects of interferon gamma (IFN- $\gamma$ ) 1b administered subcutaneously thrice weekly versus colchicine for 2 yrs. This study had no pre-specified end-points.

Fifty consecutive IPF patients were randomised. Patients with mild-to-moderate IPF were eligible for the study if they had histologically proven IPF, or, in the absence of surgical biopsy, fulfilled the European Respiratory Society/American Thoracic Society criteria.

In the intent-to-treat population, five out of 32 (15.6\%) IFN- $\gamma-1 \mathrm{~b}$ patients and seven out of 18 (38.8\%) colchicine patients died after a median follow-up period of 25 months Patients treated with IFN- $\gamma$ 1b showed a better outcome after 2 yrs of therapy, and fewer symptoms, as assessed using the St George's Respiratory Questionnaire, after 12 months of therapy. Also, the IFN- $\gamma-1 \mathrm{~b}$ group exhibited a higher forced vital capacity (percentage of the predicted value) after 24 months of treatment. No significant differences were detected in resting arterial oxygen tension, total lung capacity (\% pred), transfer factor of the lung for carbon monoxide (\% pred) and high-resolution computed tomographic scoring between the two treatment groups.

These data suggest that long-term treatment with interferon gamma 1b may improve survival and outcome in patients with mild-to-moderate idiopathic pulmonary fibrosis. Further studies are needed to verify these results.

KEYWORDS: Colchicine, idiopathic pulmonary fibrosis, interferon gamma-1b, outcome, survival, treatment

diopathic pulmonary fibrosis (IPF) or cryptogenic fibrosing alveolitis is the most common among the idiopathic interstitial pneumonias and has a dismal prognosis [1-3]. The median survival of patients with IPF is $3-5$ yrs after the onset of symptoms [4,5]. In this context, it is important to emphasise that this disorder is largely unresponsive to the currently recommended combined treatment with corticosteroids and immunosuppressives [1]. Therefore, there is a need for novel therapies to reverse or at least limit the lung fibroblast proliferation/activation and aberrant connective tissue remodelling that characterise this devastating disease $[6,7]$.

Interferon gamma (IFN- $\gamma$ ) is a potential therapeutic candidate because it regulates both macrophage and fibroblast functions [6, 8, 9]. The theoretical benefits would include diminished expression of insulin-like growth factor-I, a

For editorial comments see page 463. profibrogenic growth factor produced by macrophages, and suppression of fibroblast proliferation and collagen synthesis [9]. A recent study by STRIETER et al. [10], regarding the effects of IFN- $\gamma 1 b$, provides direct evidence that this multifunctional cytokine alters the expression of certain molecules postulated, with trends towards downregulation of fibrotic and angiogenic markers. In addition, IPF seems to be characterised by the predominant expression of T-helper cell type 2 cytokines, and IFN- $\gamma$ may shift the Th2 balance towards a Th1 profile [11].

The first observation showing the therapeutic effectiveness of IFN- $\gamma 1 \mathrm{~b}$ in IPF was reported in the small study of ZIESCHE et al. [12]. Recently, a large clinical trial in the USA failed to show a beneficial effect on progression-free survival, pulmonary function or quality of life after $1 \mathrm{yr}$ of treatment [13]. However, a subanalysis suggested that patients with less severe pulmonary function impairment showed better survival.
AFFILIATIONS

*Dept of Pneumonology, Medical School, University of Crete, Iráklion, Depts of "Pneumonology and, ${ }^{f}$ Histopathology, Sotiria Chest Hospital, and,

Depts of ${ }^{+}$Radiology and,

${ }^{\S}$ Pneumonology, Medical School, University of Athens, and,

**Dept of Pneumonology,

Sismanoglion Hospital, Athens, and,

\#\# Dept of Pneumonology, Democritus Medical School, University of Thrace, Alexandroúpolis, Greece.

\#Dept of Histopathology, Royal

Brompton Hospital, London, UK

CORRESPONDENCE

D. Bouros

Medical School

Democritus University of Thrace

68100

Alexandroupolis

Thrace

Greece

Fax: 302551076106

E-mail: bouros@med.duth.gr

Received:

March 202006

Accepted after revision:

April 052006

SUPPORT STATEMENT

The current study was supported by an unrestricted grant from Boehringer Ingelheim Hellas (Athens, Greece) and the Society for Pulmonary and Intensive Care Research in the district of East

Macedonia and Thrace

(Alexandroúpolis, Greece). The Greek National Health System supported both colchicine and interferon gamma- $1 \mathrm{~b}$. This study was previously presented, in part, at the European Respiratory

Society 13th Annual Congress, Vienna Austria, September 27-0ctober 1, 2003, and at the American Thoracic Society 99th International Conference, Seattle, WA, USA, May 16-21, 2003. K.M. Antoniou was a recipient of the Alfred Soffer Research Award at the Annual American College of Chest Physicians meeting, Orlando, FL, USA October 25-30, 2003.

European Respiratory Journal Print ISSN 0903-1936

Online ISSN 1399-3003 
Therefore, there is a need for data verification in a cohort of patients with less advanced disease and for a longer period of treatment.

Colchicine is a well-tolerated antifibrotic drug that is taken orally. Previous studies have suggested that its effects are similar to those of prednisone, with fewer side-effects, whereas median survival remains unchanged $[14,15]$. The rationale for using colchicine is its multiple effects, including arrest of cell division, inhibition of granulocyte migration and release of several proteins from cells, and blocking of the in vitro release of fibronectin from alveolar macrophages [15].

Therefore, a prospective randomised comparative trial was undertaken using IFN- $\gamma 1 \mathrm{~b}$, taken subcutaneously at a dose of $200 \mu \mathrm{g}$ three times weekly for 2 yrs, compared with colchicine, at a dose of $1 \mathrm{mg} \cdot \mathrm{day}^{-1}$ orally, in combination with low-dose prednisolone.

\section{MATERIALS AND METHODS Study subjects}

The protocol was approved by the ethics committee of the University General Hospital of Iráklion (Crete, Greece). Between March 2000 and June 2003, 68 patients were recruited from eight centres and 50 underwent randomisation after informed consent. Patients with mild-to-moderate IPF were eligible for the study if they had histologically proven IPF (usual interstitial pneumonia (UIP)) on surgical lung biopsy, or, in the absence of surgical biopsy, fulfilled the recent American Thoracic Society (ATS)/European Respiratory Society (ERS) criteria [1].

Eligible patients were aged 40-80 yrs, had shown clinical symptoms of IPF for $\geqslant 3$ months, and had a forced vital capacity (FVC) of $\geqslant 55 \%$ and $\leqslant 90 \%$ of the predicted value, a transfer factor of the lung for carbon monoxide $(T \mathrm{~L}, \mathrm{CO})$ of $\geqslant 35 \%$ pred and an arterial oxygen tension $\left(\mathrm{Pa}_{\mathrm{a}} \mathrm{O}_{2}\right)$ of $>7.3 \mathrm{kPa}$ while breathing room air at rest.

Newly diagnosed untreated symptomatic IPF patients or longdiagnosed IPF patients with a decrease in lung function of $\geqslant 10 \%$ despite continuous or repeated treatment with glucocorticoids, other immunosuppressive agents or both for $\geqslant 6$ of the previous 12 months, or evidence of worsening disease on a chest radiograph, or of worsening dyspnoea at rest or on exertion within $1 \mathrm{yr}$ before enrolment were included in the present study. Patients previously treated with IFN or colchicine were excluded from the study.

Criteria for exclusion were a significant history of exposure to organic or inorganic dust or drugs known to cause pulmonary fibrosis and connective tissue disease or other chronic lung diseases causing pulmonary fibrosis, a ratio of the forced expiratory volume in one second to FVC of $<0.6$ after bronchodilator use, a residual volume of $>120 \%$ pred, active infection within 1 week before enrolment, unstable cardiovascular or neurological disease, uncontrolled diabetes, pregnancy, lactation, any active malignancy likely to result in death or any condition other than IPF likely to result in death within 3 yrs.

Patients were categorised as nonsmokers, current smokers or ex-smokers (a minimum of 1 cigarette $\cdot$ day $^{-1}$ for a minimum of $1 \mathrm{yr}$, stopping $\geqslant 6$ months before presentation).

\section{Study design}

The present randomised, multicentric, open-label, parallelgroup, efficacy study started with a run-in period of 2 months (visits 1-2). Randomisation was performed using a random number table.

The study was originally designed to investigate the molecular perspective after both treatment regimens. Owing to technical difficulties, this aim was only investigated in a subgroup of 10 patients (data not shown). The study did not have prespecified end-points.

The study objectives were to compare the clinical effects of the two treatment regimens after 6, 12 and 24 months of therapy using: pulmonary function tests (FVC, total lung capacity (TLC), TL,CO and $\mathrm{Pa}_{2} \mathrm{O}_{2}$ at rest), the extent of lung fibrosis on high-resolution computed tomography (HRCT), quality of life (St George's Respiratory Questionnaire (SGRQ)), treatment outcome (using the ATS/ERS criteria), and overall survival.

During the run-in period, all eligible patients received $50 \mathrm{mg} \cdot$ day $^{-1}$ oral prednisolone for 4 weeks, with subsequent tapering of the dose to $10 \mathrm{mg} \cdot \mathrm{day}^{-1}$ over a 1 -month period, regardless of any previous treatment. The duration of the treatment was 24 months over eight visits. If the glucocorticoid treatment was ineffective, the patients were randomly assigned (2:1) to receive either $200 \mu \mathrm{g}$ IFN- $\gamma 1 \mathrm{~b}$ subcutaneously three times per week plus $10 \mathrm{mg}$ oral prednisolone daily for 24 months or $1 \mathrm{mg} \cdot$ day $^{-1}$ oral colchicine plus $10 \mathrm{mg}$ oral prednisolone daily for the same treatment period. No other treatments were allowed during the study. A response to corticosteroids was considered to have occurred with an increase of $>10 \%$ in FVC ( $\%$ pred) and/or TL,CO ( $\%$ pred). All new symptoms were recorded as adverse events. All patients were followed for the duration of the study regardless of whether or not they continued IFN- $\gamma 1 \mathrm{~b}$ or colchicine.

\section{Measurements}

Pulmonary function tests

All patients were evaluated spirometrically and by measurement of lung volumes, diffusion capacity and arterial blood gas levels (at rest).

Spirometry and measurement of lung volumes using the helium-dilution technique and TL,CO (corrected for the haemoglobin) using the single-breath method [16] were performed using a computerised system (Jaeger 2.12; MasterLab, Würzburg, Germany). Predicted values were obtained from the standardised lung function testing of the European Coal and Steel Community, Luxembourg (1993) [17]. Arterial blood gas determination was performed at rest using an arterial blood gas analyser (AVL330; MasterLab system).

\section{HRCT evaluation}

Scoring of disease extent and progression

Two readers, blinded to the clinical functional data and type of treatment, examined the HRCT images. HRCT slices from five predetermined levels (the great vessels, the aortic arch, the carina, the right inferior pulmonary vein and $2 \mathrm{~cm}$ above the right hemidiaphragm) were evaluated. 


\section{HRCT extent of disease score}

At each level, the overall extent of disease was visually estimated to the nearest $5 \%$, including a reticular pattern or ground-glass opacification with or without traction bronchiectasis. In order to obtain the mean fibrosis score, percentages from all slices examined were summed and divided by the number of slices (five). This mean (range 0-100\%) was considered the extent of fibrosis, irrespective of the predominant pattern. This visual method of disease extent quantification has been extensively used for HRCT scoring in interstitial lung disease with good functional correlations by WELLS and co-workers $[18,19]$.

\section{HRCT disease progression score}

Repeat HRCT studies at 12 months after initiation of treatment were compared with those performed at baseline. HRCT changes were measured on a scale of 1-5, representing likelihood of improvement or deterioration (HRCT progress score). A score of 1 indicated definite improvement, a score of 2 indicated that subtle improvement was most likely, a score of 4 was given when subtle or little deterioration was most likely, and a score of 5 when definite deterioration was seen. Stable disease was recorded as 3 . This scoring system forms a fivepoint scale for disease changes in each HRCT slice (range 5-25 for each patient). In order to obtain the mean HRCT disease progression score, the rating values from all slices examined were summed and divided by the number of slices (five).

Definite improvement was agreed to be recognised when unquestionable resolution of ground glass or interstitial abnormalities was seen. Definite deterioration was recognised when unquestionable new areas of ground-glass opacities or reticulation emerged or when a microcystic reticular pattern changed into macrocystic disease (coarsening of reticulation to honeycomb) or unquestionable traction bronchiectasis had developed in an area of previous ground-glass opacification. In addition, consensus agreement upon level of certainty (either towards improvement or deterioration, notably scores of 1 or 5 , respectively) was agreed also to be based upon the relative predominance of the above signs of improvement or deterioration within each individual slice.

In addition, the extent of emphysema was visually estimated at each level to the nearest $5 \%$, first independently and then by consensus. The mean (range 1-100\%) was considered to be the extent of emphysema.

Finally, a qualitative comment on the type of change was noted, including: 1) ground-glass development or resolution, 2) reticulation development or resolution, and 3) coarsening of the reticulation (microcystic reticular pattern replaced by macrocystic disease). The above qualitative parameters were roughly quantitatively characterised overall [20, 21].

\section{Outcome}

Outcome was evaluated according to the established ATS/ERS criteria [1]. A favourable (or improved) and a stable (and presumed favourable) response to treatment were classified as improvement or stabilisation of outcome in each separate patient. Symptoms (dyspnoea and cough), HRCT and physiological evaluation (changes of $10 \%$ for FVC and TLC, and $>15 \%$ for $\mathrm{TL}, \mathrm{CO}$ and $0.53 \mathrm{kPa}$ (for $\mathrm{Pa}, \mathrm{O}_{2}$ ) were measured in each patient at the different time-points of the study. Symptomatology and pulmonary function test (PFT) results were measured at baseline and at 3-month intervals and classified as improved, stable and deteriorated, according to the above criteria [1]. Disease progression was evaluated by HRCT after 6, 12 and/or 24 months of treatment.

In detail, a favourable (or improved), stable or failed response to therapy is defined by two or more of the following, documented on two consecutive visits over a 3-6-month period, respectively: 1) decreased, stable or increased symptoms (dyspnoea and/or cough); 2) reduced, stable or increased parenchymal abnormalities on HRCT scan; and 3) physiological improvement, stability or deterioration, defined by two or more of the following: 1) $>10 \%$ increase in TLC or FVC; 2) $>15 \%$ increase in $\mathrm{TL}, \mathrm{CO}$; and 3) an improvement in $\mathrm{Pa}_{\mathrm{a}} \mathrm{O}_{2}$, with a $>0.53 \mathrm{kPa}$ increase from the previous measurement.

\section{Quality of life}

The quality of life of patients was investigated using the SGRQ, before and after 12 months of treatment [22, 23].

\section{Symptomatology}

Assessment of dyspnoea was effected by the modified UK Medical Research Council (MRC) dyspnoea scale, a four-point scale for evaluating this symptom [24]. The status of cough was evaluated (as dry, productive or absent) at baseline and at 3month intervals and classified as improved, stable and deteriorated.

\section{Statistical analysis}

Comparisons between and within groups were made using an unpaired t-test, paired t-test, Wilcoxon rank-sum test, MannWhitney U-test or Chi-squared test as appropriate. Comparisons for the different outcomes (PFTs and quality-oflife parameters) at each time-point were made using the ANCOVA test for repeated measurements. Survival estimation was performed using Kaplan-Meier analysis. Comparisons of survival between two groups were made using the log rank test, whereas Cox regression analysis was used to adjust for possible covariates. A p-value of $\leqslant 0.05$ was considered to indicate significance [25, 26].

\section{RESULTS}

Of 68 patients screened, 50 were included in the study and underwent randomisation; 32 patients received IFN- $\gamma 1 \mathrm{~b}$ and 18 colchicine. Twelve patients were excluded because they did not meet all of the entry criteria and the other six because they responded to corticosteroids. All patients remained in the study until January 2004, unless withdrawn for other reasons (death, clinical worsening or social/personal reasons). Baseline patient characteristics are shown in table 1. In the first group (IFN- $\gamma 1 b$ ), the incident/prevalent ratio was 19:13 (incident cases 59\%) and in the second group 12:6 (incident cases 66\%; $\mathrm{p}=0.4$ ). No imbalances in HRCT evaluation were apparent at baseline (table 1). The diagnosis was confirmed by the identification of UIP on surgical lung biopsy in $84 \%$ (27) of patients in the IFN- $\gamma-1$ broup and in $83 \%$ (15) in the colchicine group. The median duration of treatment was 20 months (range 2-44 months) in the IFN- $\gamma-1 b$ group and 15 months (range 5-44 months) in the colchicine group. Clubbing was 


\begin{tabular}{|c|c|c|c|}
\hline & IFN- $\gamma$ 1b & Colchicine & p-value ${ }^{\#}$ \\
\hline Subjects n & 32 & 18 & \\
\hline Age yrs & $66(54-85)$ & $69(42-82)$ & \\
\hline Incident/prevalent ratio & 19:13 & $12: 6$ & 0.4 \\
\hline \multicolumn{4}{|l|}{ Sex $n$} \\
\hline Male & 29 & 13 & \\
\hline Female & 3 & 5 & \\
\hline \multicolumn{4}{|l|}{ Smoking status } \\
\hline Smokers & $3(9.4)$ & $1(5.6)$ & 0.85 \\
\hline Ex-smokers & $16(50.0)$ & $9(50.0)$ & \\
\hline Never smokers & $12(37.5)$ & $8(44.4)$ & \\
\hline $\begin{array}{l}\text { Time since first symptom } \\
\text { months }\end{array}$ & $49.4 \pm 24.3$ & $42.7 \pm 16.8$ & 0.46 \\
\hline Duration of treatment months & $20.25 \pm 11.3$ & $16.3 \pm 11$ & 0.24 \\
\hline Follow-up months & $28.2 \pm 11.1$ & $20.3 \pm 12.2$ & 0.52 \\
\hline FVC \% pred & $71.8 \pm 15.0$ & $70.7 \pm 17.7$ & 0.82 \\
\hline TLC \% pred & $62.8 \pm 15.9$ & $63.2 \pm 13.8$ & 0.92 \\
\hline$T L, C O \%$ pred & $54.5 \pm 18.1$ & $51.1 \pm 18.9$ & 0.54 \\
\hline $\mathrm{Pa}_{\mathrm{a}, \mathrm{O}_{2}} \mathrm{mmHg}$ & $75.4 \pm 17.0$ & $69.5 \pm 14.3$ & 0.20 \\
\hline Extent of fibrosis on HRCT \% & $32.9 \pm 8.7$ & $40 \pm 12.2$ & 0.18 \\
\hline \multicolumn{4}{|c|}{$\begin{array}{l}\text { Data are presented as median (range), } \mathrm{n}(\%) \text { or mean } \pm \mathrm{SD} \text {, unless otherwise } \\
\text { indicated. IFN- } \gamma 1 \mathrm{~b} \text {; interferon gamma- } 1 \mathrm{~b} \text {; } \mathrm{FVC} \text { : forced vital capacity; \% pred: } \\
\text { percentage of predicted; } \mathrm{TLC} \text { : total lung capacity; } \mathrm{TL}, \mathrm{CO} \text { : transfer factor of the } \\
\text { lung for carbon monoxide; } \mathrm{Pa}_{\mathrm{a}} \mathrm{O}_{2} \text { : arterial oxygen tension; HRCT: high-resolution } \\
\text { computed tomography. }{ }^{*} \text { : from independent two-sample t-tests for continuous } \\
\text { data and Chi-squared tests for categorical data. } 1 \mathrm{mmHg}=0.133 \mathrm{kPa} \text {. }\end{array}$} \\
\hline
\end{tabular}

present in $13(40.6 \%)$ IFN- $\gamma-1 b$ patients and nine $(50 \%)$ colchicine patients $(\mathrm{p}=0.52)$.

\section{Survival}

The vital status of all randomised patients was ascertained at the time of study completion. In the intent-to-treat population, five out of $32(15.6 \%)$ IFN- $\gamma-1 b$ patients and seven out of 18 $(38.8 \%)$ colchicine patients had died $(\mathrm{p}=0.028)$. Mean survival was 39 months (95\% confidence interval (CI) 35-43 months) for the IFN- $\gamma-1 b$ group and 30 months (22-38 months) for the colchicine group (fig. 1). The hazard ratio for death in the IFN$\gamma-1 b$ group, compared with the colchicine group, was $0.30(95 \%$ CI 0.07-0.86). Cox regression analysis showed that the difference between the two groups remains significant after adjustment for age and comorbid conditions $(p=0.04)$. Subanalysis suggested that the effect of treatment on the risk of death depended on the FVC at baseline. Among patients with a baseline FVC above the median ( $\geqslant 71 \%$ pred), none of the IFN- $\gamma-1 b$ patients died, compared with $44 \%$ of the nine patients in the colchicine group $(p=0.008$; fig. 2$)$. Conversely, among 25 patients with a baseline FVC that was $<71 \%$ pred, no survival benefit was apparent $(\mathrm{p}=0.68)$. Among patients with a baseline $T \mathrm{~L}, \mathrm{CO}$ that exceeded the median ( $\geqslant 51 \%$ pred), no IFN- $\gamma-1 b$-treated patient died, compared with $30 \%$ in the colchicine group ( $\mathrm{p}=0.028$; fig. 3 ).

Respiratory insufficiency or disease progression accounted for three out of the five IFN- $\gamma-1 b$ patients who died and for five

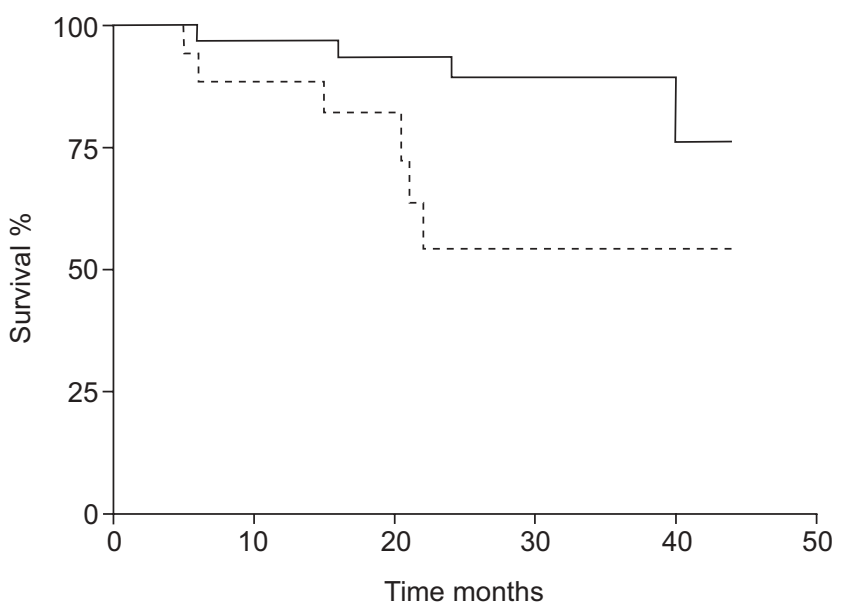

FIGURE 1. Kaplan-Meier survival curve among patients with idiopathic pulmonary fibrosis. __ : interferon gamma- $1 \mathrm{~b}$ treatment $(n=32)$; ------: colchicine treatment $(n=18)$. Vertical bars represent deaths. $p=0.028$.

out of the seven patients in the colchicine group. The other causes of death were lower respiratory tract infections. Pseudomonas aeruginosa was cultured in two cases.

\section{Outcome}

After 6 months of treatment, 24 (75\%) patients in the IFN- $\gamma-1 b$ group showed improvement or stabilisation of their disease compared with seven $(41 \%)$ in the colchicine group $(\mathrm{p}=0.022)$. After 24 months of treatment, $61.9 \%$ of IFN $-\gamma-1 b$ patients had improved or stabilised compared with $16.7 \%$ of colchicine patients $(\mathrm{p}=0.014$; table 2$)$. Individual assessment of the three criteria used in this study is shown in figure 4 .

\section{Pulmonary function tests}

No significant differences in lung mechanics, lung volumes, $T \mathrm{~L}, \mathrm{CO}$ and $\mathrm{Pa}, \mathrm{O}_{2}$ were found between the two groups after 6 and 12 months of treatment (table 3). A significant difference in FVC (\% pred) was detected after 24 months of treatment, in

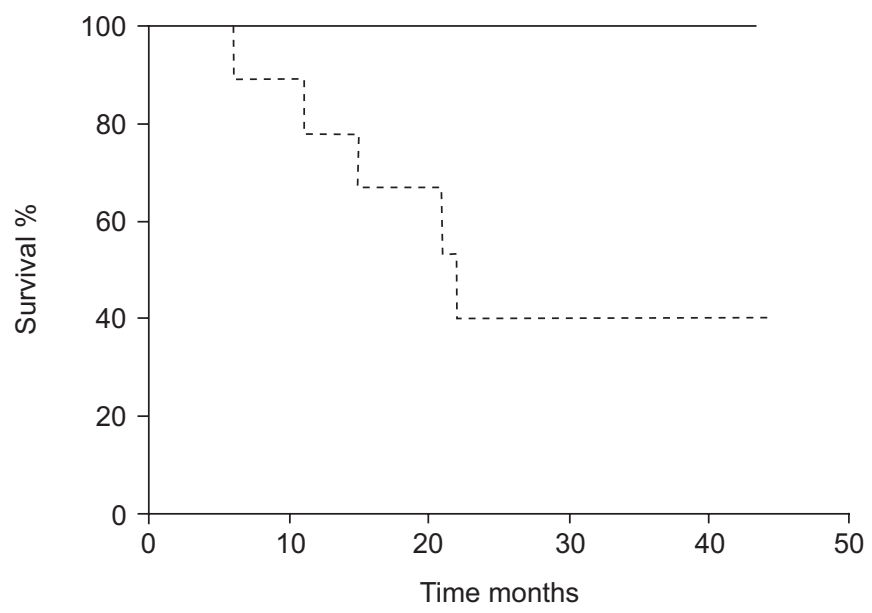

FIGURE 2. Kaplan-Meier survival curve among idiopathic pulmonary fibrosis patients. ——: interferon gamma-1b treatment $(n=16)$; ------: colchicine treatment $(n=9)$ with a forced vital capacity of $>71 \%$ of the predicted value. Vertical bars represent deaths. $p=0.008$. 


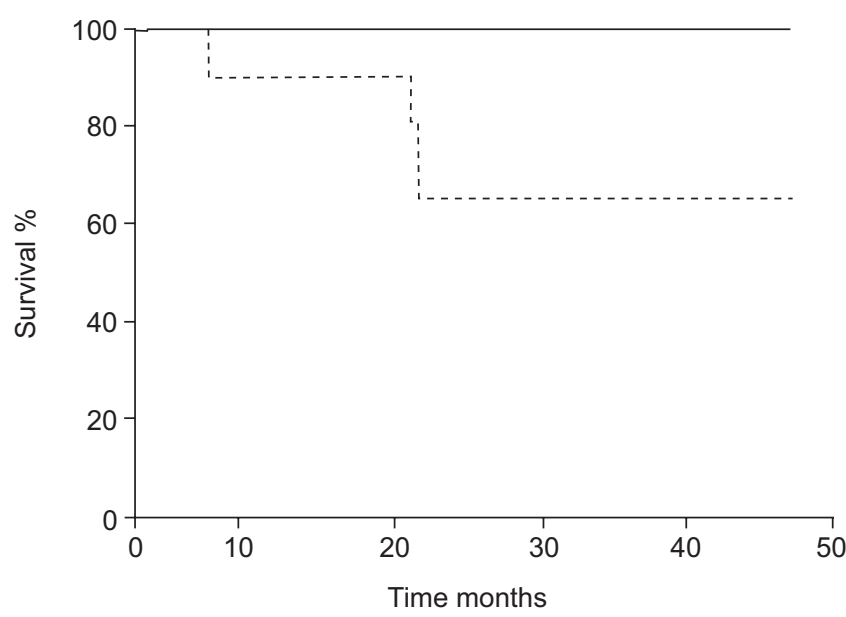

FIGURE 3. Kaplan-Meier survival curve among idiopathic pulmonary fibrosis patients. —_: interferon gamma-1b treatment $(n=16)$; ------: colchicine treatment $(n=10)$ with a transfer factor of the lung for carbon monoxide of $>51 \%$ of the predicted value. Vertical bars represent deaths. $p=0.03$.

favour of the IFN- $\gamma-1 \mathrm{~b}$ group (table 3 ). Mean FVC (\% pred) and $\mathrm{Pa}_{\mathrm{a}} \mathrm{O}_{2}$ at three time-points in the study are shown in figure 5 .

\section{HRCT scoring}

Overall, for the entire cohort of patients $(n=50)$, the mean $\pm S D$ baseline extent of fibrosis using HRCT scoring was $35.3 \pm 10.45 \%$ (range $14-59 \%$ ). For the IFN- $\gamma$ - 1 b-treatment group, the baseline extent of fibrosis on HRCT scoring was $32.9 \pm 8.7 \%$ (range $14-48 \%$ ), and, for the colchicine group, $40 \pm 12.2 \%$ (range $23-59 \%$ ). There was no significant difference in mean HRCT extent of disease score between the groups at baseline $(\mathrm{p}=0.184$, Mann-Whitney U-test). The mean HRCT progression score from both readers was $3.72 \pm 0.73 \%$ (range $1.9-4.9 \%$ ). There were no differences in progression score between the two groups after 12 months of treatment in 27 patients treated with IFN- $\gamma 1 \mathrm{~b}$ and in 14 patients in the colchicine arm $(p=0.14)$. Furthermore, no marked differences were found in disease severity score between the two groups after 6 (13 IFN- $\gamma$ 1b and nine colchicine patients, $p=0.08)$ and 24 months of treatment (16 IFN- $\gamma 1 \mathrm{~b}$ and five colchicine patients, $\mathrm{p}=0.4$ ).

\section{Symptomatology and quality of life}

Neither dyspnoea, as assessed by the modified MRC scale, nor cough differed between the two treatment groups at each

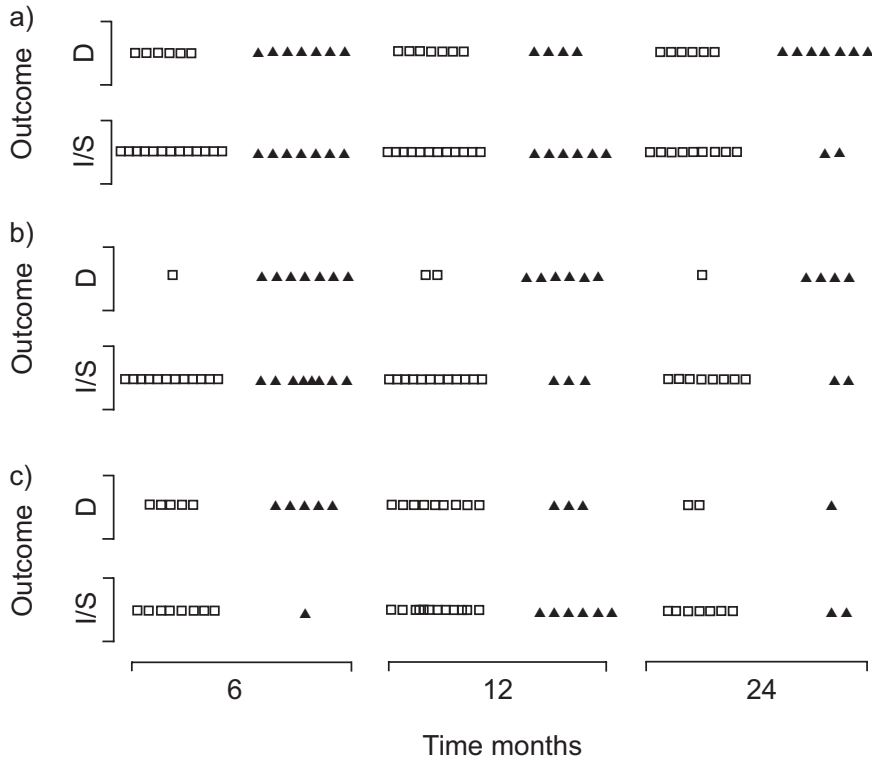

FIGURE 4. Improvement/stability (I/S) or deterioration (D) of: a) dyspnoea scale; b) pulmonary function test results/arterial oxygen tension; and c) highresolution computed tomography score in idiopathic pulmonary fibrosis patients receiving interferon gamma-1b $(\square)$ and colchicine $(\boldsymbol{\Lambda})$ at 6,12 and 24 months of follow-up.

time-point. Nonetheless, quality of life, according to the SGRQ as regards symptomatology, was significantly better after 12 months only in the IFN- $\gamma$ group (table 4 ).

\section{Adverse reactions}

Constitutional symptoms, such as fever, myalgia, rigors, headache and flu-like syndrome, were significantly more common among patients who received IFN- $\gamma(\mathrm{p}<0.01)$, whereas mild diarrhoea was observed in only two patients in the colchicine group. None of the above symptoms were lifethreatening. In the majority of patients, the IFN- $\gamma$-related symptoms subsided within the first 9-12 weeks. Indeed, in some of the present patients, the drug was well tolerated after the first few administrations. Respiratory tract infections were observed in eight patients in the IFN- $\gamma$ group and two in the colchicine group. There were 12 recorded hospitalisations, eight $(25 \%)$ in the IFN- $\gamma-1 b$ group and four in the colchicine group $(\mathrm{p}=0.8)$.

\section{TABLE 2 Outcome at 6, 12 and 24 months of treatment ${ }^{\#}$}

\begin{tabular}{|c|c|c|c|c|c|c|}
\hline & \multicolumn{3}{|c|}{ IFN- $\gamma$ 1b } & \multicolumn{3}{|c|}{ Colchicine } \\
\hline & 6 months & 12 months & 24 months & 6 months & 12 months & 24 months \\
\hline Subjects & 32 & 29 & 21 & 17 & 11 & 12 \\
\hline Improvement/stability & $24(75)^{\bullet}$ & $18(62)$ & $13(62)^{+}$ & $7(41)$ & $5(45)$ & $2(17)$ \\
\hline Deterioration & $8(25)$ & 11(38) & $8(38)$ & $10(59)$ & $6(55)$ & $10(83)$ \\
\hline
\end{tabular}

Data are presented as $n$ or $n(\%)$. IFN- $\gamma$ 1b: interferon gamma-1b. ${ }^{*}:$ according to American Thoracic Society/European Respiratory Society criteria [1]. ${ }^{\bullet} \mathrm{p}=0.02 ;$ $p=0.01$ versus colchicine 


\begin{tabular}{|c|c|c|c|}
\hline \multirow[t]{2}{*}{ TABLE 3} & \multicolumn{3}{|c|}{$\begin{array}{l}\text { Changes }(\Delta) \text { in pulmonary function }{ }^{\#} \text { after } 6,12 \\
\text { and } 24 \text { months of treatment }\end{array}$} \\
\hline & IFN- $\gamma 1 \mathrm{lb}$ & Colchicine & p-value \\
\hline \multicolumn{4}{|l|}{$\Delta F V C \%$ pred } \\
\hline 6 months & $-1.3(-3.9-1.3 ; 28)$ & $-1.9(-3.7-3.9 ; 17)$ & 0.7 \\
\hline 12 months & $-1.6(-5.2-2.0 ; 25)$ & $-9.3(-15.9--2.6 ; 11)$ & 0.06 \\
\hline 24 months & $1.7(-2.4-5.7 ; 13)$ & $-7.1(-18.7--4.5 ; 5)$ & 0.04 \\
\hline \multicolumn{4}{|l|}{$\Delta \mathrm{TLC} \%$ pred } \\
\hline 6 months & $-0.4(-4.2-3.4 ; 25)$ & $-4.0(-12.0-3.9 ; 17)$ & 0.4 \\
\hline 12 months & $-2.3(-6.0-1.4 ; 24)$ & $-6.8(-16.0-2.8 ; 11)$ & 0.5 \\
\hline 24 months & $-1.7(-9.0-5.6 ; 13)$ & $1.0(-8.6-10.6 ; 5)$ & 0.2 \\
\hline \multicolumn{4}{|c|}{$\Delta T \mathrm{~L}, \mathrm{CO} \%$ pred } \\
\hline 6 months & $-0.5(-4.4-3.4 ; 25)$ & $2.3(-2.9-7.5 ; 16)$ & 0.5 \\
\hline 12 months & $-1.5(-7.0-4.0 ; 24)$ & $0.96(-9.4-11.4 ; 10)$ & 0.8 \\
\hline 24 months & $-6.8(-13.0--0.3 ; 13)$ & $1.2(-20.7-23.0 ; 5)$ & 0.3 \\
\hline \multicolumn{4}{|l|}{$\Delta \mathrm{Pa}, \mathrm{O}_{2} \mathrm{mmHg}$} \\
\hline 6 months & $-2.9(-7.4-1.4 ; 28)$ & $-1.8(-4.7-1.0 ; 17)$ & 0.7 \\
\hline 12 months & $-4.9(-8.6--1.2 ; 25)$ & $-5.9(-12.5-0.7 ; 11)$ & 0.1 \\
\hline 24 months & $-2.4(-11.4-6.6 ; 12)$ & $-3.9(-13.3-5.5 ; 5)$ & 0.1 \\
\hline \multicolumn{4}{|c|}{$\begin{array}{l}\text { Data are presented as mean ( } 95 \% \text { confidence interval; } n \text { ). IFN- } \gamma 1 \mathrm{~b} \text { : interferon } \\
\text { gamma-1b; FVC: forced vital capacity; \% pred: percentage of predicted; TLC: } \\
\text { total lung capacity; } T \mathrm{~L} \text {, } \mathrm{CO} \text { : transfer factor of the lung for carbon monoxide; } \mathrm{Pa}_{\mathrm{a}} \mathrm{O}_{2} \text { : } \\
\text { arterial oxygen tension. }{ }^{\#} \text { : from baseline using ANCOVA (negative and positive } \\
\text { values represent deterioration and improvement from baseline, respectively). } \\
1 \mathrm{mmHg}=0.133 \mathrm{kPa} \text {. }\end{array}$} \\
\hline
\end{tabular}

In total, 17 (11 in the IFN- $\gamma-1 b$ group and six in the colchicine group) of the 50 patients discontinued treatment before 24 months. Of the 11 patients in the IFN- $\gamma-1 b$ group, eight stopped because of an adverse event and/or disease progression and three for social reasons. Of the colchicine group, six patients withdrew; two stopped because of disease progression and four for social reasons.

\section{DISCUSSION}

The present study is the only study in the literature comparing IFN- $\gamma 1 \mathrm{~b}$ and colchicine. It is also the second-largest study

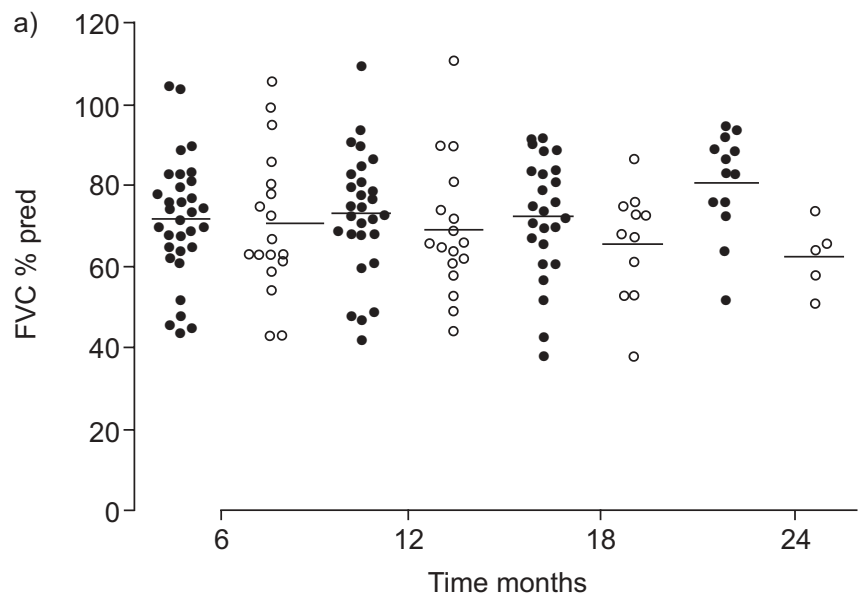

\begin{tabular}{|c|c|c|c|}
\hline \multirow[t]{2}{*}{ TABLE 4} & \multicolumn{3}{|c|}{$\begin{array}{l}\text { Changes }(\Delta) \text { in St George's Respiratory } \\
\text { Questionnaire scores }{ }^{\#} \text { before and after } 12 \\
\text { months of treatment }\end{array}$} \\
\hline & IFN- $\gamma$ 1b & Colchicine & p-value \\
\hline$\Delta$ Symptoms & $-13.2(-21.4--5.0)$ & $7.5(-4.5-19.5)$ & 0.01 \\
\hline$\Delta$ Activity & $-4.8(-12.7-3.0)$ & $4.7(-12.1-22.0)$ & 0.3 \\
\hline$\Delta$ Impacts & $-1.9(-9.2-5.4)$ & $4.1(-6.4-14.6)$ & 0.3 \\
\hline$\Delta$ Total score & $-4.7(-11.4-2.0)$ & $4.8(-5.9-15.5)$ & 0.3 \\
\hline
\end{tabular}

Data are presented as mean (95\% confidence interval). IFN- $\gamma$ 1b: interferon gamma-1b. *: using ANCOVA (negative and positive values represent deterioration and improvement from baseline, respectively) in the IFN- $\gamma 1 \mathrm{~b}$ $(n=20)$ and colchicine $(n=7)$ groups

exploring the therapeutic role of IFN- $\gamma 1 \mathrm{~b}$ in patients with IPF. In this well-defined patient population, an apparent beneficial effect of IFN- $\gamma 1$ b on survival, outcome and FVC (\% pred), after a 24-month treatment, was observed compared with colchicine.

On the one hand, the major finding of the present study was the apparent survival benefit in the IFN- $\gamma-1 \mathrm{~b}$ group compared with the colchicine group. A recent retrospective analysis, performed in order to optimise selection of the end-point criteria for the study of RAGHU et al. [13], showed that mortality was the most inclusive end-point for future trials involving IFN- $\gamma 1 b$ [27].

On the other hand, several limitations exist in the design of the present study. First, there were no specific pre-specified endpoints, and hence no power calculations were undertaken for the sample size. Secondly, but no less importantly, this study was not placebo-controlled. Additional major limitations include the very small group of patients who had received $>2$ yrs of treatment and the analysis of the lung function data in a limited number of patients remaining in the study for $>2$ yrs.

Conversely, no survival benefit was found with colchicine. The present study is the second randomised study that provides

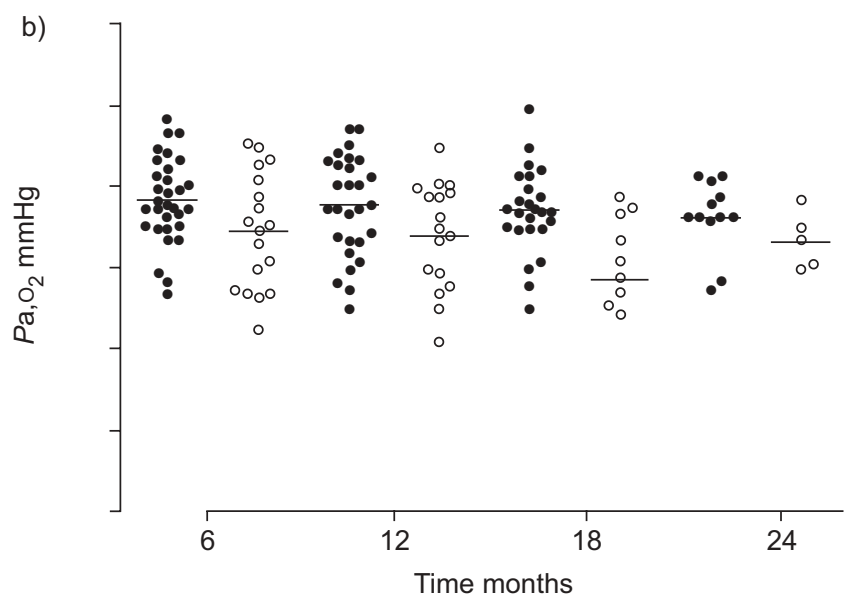

FIGURE 5. a) Forced vital capacity ( $\mathrm{FVC})$ and b) arterial oxygen tension $\left(\mathrm{Pa}_{1} \mathrm{O}_{2}\right)$ in interferon gamma-1b ) and colchicine ( $\bigcirc$ ) groups at 6, 12 and 24 months. Individual values are shown; horizontal bars represent means. $1 \mathrm{mmHg}=0.133 \mathrm{kPa}$. 
data affirming the inefficacy of colchicine in the treatment of IPF. In the first randomised study, Douglas et al. [28] found that neither prednisone nor colchicine resulted in objective improvement, and the disease continued to progress. Colchicine appears to be a safer alternative than a trial of high-dose prednisone, but may be no different to no therapy [14]. The use of colchicine instead of placebo could be a valid alternative in certain cases. With the present data, there is no evidence to suggest a beneficial role for colchicine in the treatment of IPF.

In addition, a rigorous attempt to make an accurate diagnosis was undertaken. A strength of the study is the high percentage $(85 \%)$ of patients receiving surgical lung biopsy confirmation of IPF and pathological evaluation following the new classification of idiopathic interstitial pneumonias by an expert pulmonary pathologist. Additionally, the duration of followup, with a mean of 2 yrs, is another strength of this trial, as well as the ascertainment of the status of all patients in a randomised and multicentric enrolment.

An additional finding of the present study is the significant difference in FVC in favour of IFN- $\gamma 1 \mathrm{~b}$ treatment after 24 months of treatment. Importantly, KING et al. [27] found that a fall in FVC of $>10 \%$ pred was both reliable and predictive of mortality. Moreover, both COLLARD et al. [29] and FLAHERTY et al. [30] identified a decrease of $\geqslant 10 \%$ pred in FVC at 6 months as predictive of mortality in recent reports.

Quality of life was significantly improved in the IFN- $\gamma$ group as regards the symptoms component of the SGRQ. Although this questionnaire is not specific for interstitial lung diseases [23], it has recently been demonstrated that the SGRQ is a sensitive tool for assessing health-related quality of life in IPF patients [31]. Interestingly, lung volumes (FVC and TLC) and duration of disease correlated with SGRQ score [31]. However, others failed to find any difference [12].

Moreover, although HRCT has been used as one of the multiple parameters [32] for evaluating response to IFN- $\gamma$ treatment, there were no published studies focusing on longitudinal changes in HRCT features of UIP in patients receiving this treatment. A recently published study showed that extent of reticulation on HRCT is an important independent predictor of mortality in patients with IPF, confirming once again the crucial role of this tool [33]. Importantly, the same study provides evidence that treatment assignment to IFN- $\gamma 1 \mathrm{~b}$ significantly reduced the risk of death in this group of patients [33].

The mechanism by which survival may be prolonged by this pleiotropic cytokine is unclear. Recent findings suggest that mortality in patients with IPF could potentially be altered by IFN- $\gamma 1 \mathrm{~b}$ through antimicrobial, antiangiogenic, antifibrotic and/or immunomodulatory effects [10]. In addition, the better survival in the IFN- $\gamma$ group may be explained by the mild-tomoderate disease (median FVC $71 \%$ pred, median TL,CO 51\% pred) of the present patients, and possibly also the longer period of treatment. The recent report of RAGHU et al. [13], which included patients with more advanced disease, failed to show a survival difference between the IFN- $\gamma$ and placebo groups. However, a secondary analysis suggested that the effect of treatment on risk of death depended on FVC at baseline, and that treatment appeared to have had a greater effect on survival among patients with less severe impairment in lung function than among those with more severe disease. These observations indicate that IFN $-\gamma 1 \mathrm{~b}$ may be beneficial only in patients with mild-to-moderate disease [13].

Two small retrospective noncomparative [34, 35] and one prospective noncomparative study [36] of IFN- $\gamma$ therapy for IPF have shown controversial results regarding the usefulness of IFN- $\gamma$ therapy. KALRA et al. [34] observed symptomatic and functional improvement in only one out of the 21 patients treated. Similarly, PRASSE et al. [36] found improvement in physiological function in only one of five patients. In contrast, NATHAN et al. [35] reported that, paradoxically, patients with advanced disease appear to derive the most benefit from IFN- $\gamma$ therapy.

Three patients in the IFN- $\gamma-1 b$ arm died with respiratory failure. As is already known, data on the natural history of IPF are sparse and the cause of clinical deterioration is often unclear. Disease progression is difficult to distinguish from complications of the disease and adverse effects of treatment. HONORE et al. [37] reported respiratory failure and alveolar opacities in four IPF patients after initiation of IFN- $\gamma-1 b$ therapy. This possibility is considered more plausible in patients with severe disease [38]. Moreover, novel data suggest that rapid respiratory decompensation in patients with mildto-moderate IPF is substantially more common than is currently perceived [39].

In conclusion, the present data suggest that interferon gamma$1 \mathrm{~b}$ may improve survival and outcome in a well-defined subpopulation of idiopathic pulmonary fibrosis patients. The apparent beneficial role of interferon gamma- $1 b$ may be restricted to patients with mild-to-moderate disease, based on measurements of pulmonary function. The present authors' view is that long-term administration of interferon gamma- $1 \mathrm{~b}$ is required in order to achieve clinical effects on disease course. However, the current results should not be overestimated, and, because of the limitations of this study, conclusions regarding the treatment effects of interferon gamma- 1 b cannot be drawn from the present results. The results of the ongoing long-term INSPIRE (International Study of Survival Outcomes in Idiopathic Pulmonary Fibrosis with Interferon gamma-1b Early Intervention) clinical trial will, hopefully, clarify whether or not interferon gamma- $1 b$ is efficacious in patients with idiopathic pulmonary fibrosis.

\section{ACKNOWLEDGEMENTS}

The authors gratefully acknowledge N.M. Siafakas and A. Wells for their continuous help in the realisation of this study. The authors would also like to thank N. Bachlitzanakis, Ch. Lambrakis, J. Drositis, G. Birba, D. Mermigkis, Ch. Mermigkis, I. Lambiri, G. Maltezakis and G. Meletis for the recruitment and evaluation of patients. The authors particularly thank the histopathologist A. Koutsopoulos for input in this study.

\section{REFERENCES}

1 American Thoracic Society. Idiopathic pulmonary fibrosis: diagnosis and treatment. International consensus statement. Am J Respir Crit Care Med 2000; 161: 646-664. 
2 American Thoracic Society. American Thoracic Society/ European Respiratory Society International Multidisciplinary Consensus Classification of the Idiopathic Interstitial Pneumonias. Am J Respir Crit Care Med 2002; 165: 277-304.

3 Bouros D. Current classification of idiopathic interstitial pneumonias. Monaldi Arch Chest Dis 2000; 55: 450-454.

4 Bjoraker JA, Ryu JH, Edwin MK, et al. Prognostic significance of histopathologic subsets in idiopathic pulmonary fibrosis. Am J Respir Crit Care Med 1998; 157: 199-203.

5 King TE Jr, Tooze JA, Schwarz MI, Brown KR, Cherniack RM. Predicting survival in idiopathic pulmonary fibrosis: scoring system and survival model. Am J Respir Crit Care Med 2001; 164: 1171-1181.

6 Antoniou KM, Ferdoutsis E, Bouros D. Interferons and their application in the diseases of the lung. Chest 2003; 123 : 209-216.

7 Bouros D, Antoniou KM. Current and future approaches in idiopathic pulmonary fibrosis. Eur Respir J 2005; 16: 693-703.

8 Mason RJ, Schwarz MI, Hunninghake GW, Musson RA. Pharmacological therapy for idiopathic pulmonary fibrosis. Am J Respir Crit Care Med 1999; 160: 1771-1777.

9 Gurujeyalakshmi G, Giri SN. Molecular mechanisms of antifibrotic effect of interferon gamma in bleomycin-mouse model of lung fibrosis: downregulation of TGF- $\beta$ and procollagen I and III gene expression. Exp Lung Res 1995; 21: 791-780.

10 Strieter RM, Starko KM, Enelow RI, Noth I, Valentine VG. Effects of interferon $\gamma-1 b$ on biomarker expression in idiopathic pulmonary fibrosis patients. Am J Respir Crit Care Med 2004; 170: 133-140.

11 Antoniou KM, Alexandrakis M, Sfiridaki K, et al. Th1 cytokine pattern (IL-12 and IL-18) in bronchoalveolar lavage fluid (BALF) before and after treatment with interferon gamma-1b (IFN- $\gamma-1 b)$ or colchicine in patients with idiopathic pulmonary fibrosis (IPF/UIP). Sarcoidosis Vasc Diffuse Lung Dis 2004; 21: 105-110.

12 Ziesche R, Hofbauer E, Wittman K, Petkov V, Block LH. A preliminary study of long-term treatment with interferon gamma-1b and low-dose prednisolone in patients with idiopathic pulmonary fibrosis. N Engl J Med 1999; 341: 1264-1269.

13 Raghu G, Brown KK, Bradford WZ, et al. A placebocontrolled trial of interferon gamma- $1 \mathrm{~b}$ in patients with idiopathic pulmonary fibrosis. N Engl J Med 2004; 350: 125-133.

14 Douglas WW, Ryu JH, Schoeder DR. Impact of oxygen and colchicine, prednisone, or no therapy on survival. Am J Respir Crit Care Med 2000; 161: 1172-1178.

15 Addrizzo-Harris DJ, Harkin TJ, Tchou-Wong KM, et al. Mechanisms of colchicine effect in the treatment of asbestosis and idiopathic pulmonary fibrosis. Lung 2002; 180: 61-72.

16 American Thoracic Society. Lung function testing: selection of reference values and interpretative strategies. Am Rev Respir Dis 1991; 144: 1202-1218.

17 Quanjer PH, Tammeling GJ, Cotes JE, et al. Lung volumes and forced ventilatory flows. Eur Respir J 1993; 16: Suppl. 6, $5-40$.
18 Wells AU, King AD, Rubens MB, Cramer D, du Bois RM Hansell DM. Lone cryptogenic fibrosing alveolitis: a functional-morphologic correlation based on extent of disease on thin-section computed tomography. Am J Respir Crit Care Med 1997; 155: 1367-1375.

19 Wells AU, Hansell DM, Rubens MB, Cullinan P, Black CM, $\mathrm{du}$ Bois RM. The predictive value of appearances on thinsection computed tomography in fibrosing alveolitis. Am J Respir Crit Care Med 1993; 148: 1076-1082.

20 Remy-Jardin M, Giraud F, Remy J, Copin MC, Gosselin B, Duhamel A. Importance of ground-glass attenuation in chronic diffuse infiltrative lung disease: pathologic-CT correlation. Radiology 1993; 189: 693-698.

21 Austin JH, Muller NL, Friedman PJ, et al. Glossary of terms for CT of the lungs: recommendations of the Nomenclature Committee of the Fleischner Society. Radiology 1996; 200: 327-331.

22 Jones PW, Quirk FH, Baveystock CM. The St George's Respiratory Questionnaire. Respir Med 1991; 85: Suppl. B, 25-31.

23 Bouros D, Psathakis K, Siafakas NM. Quality of life in interstitial lung disease. Eur Respir Rev 1997; 7: 66-70.

24 Mahler DA, Wells CK. Evaluation of clinical methods for rating dyspnea. Chest 1988; 93: 580-586.

25 Kalbfleisch JD, Prentice RL. Statistical Analysis of Failure Time Data. New York, NY, Wiley, 1980.

26 Pocock SJ, Clayton TC, Altman DG. Survival plots of timeto-event outcomes in clinical trials: good practice and pitfalls. Lancet 2002; 359: 1686-1689.

27 King TE Jr, Safrin S, Starko KM, et al. Analyses of efficacy end points in a controlled trial on interferon- $\gamma 1 b$ for idiopathic pulmonary fibrosis. Chest 2005; 127: 171-177.

28 Douglas WW, Ryu JII, Swensen SJ, et al. Colchicine versus prednisone in the treatment of idiopathic pulmonary fibrosis: a randomised prospective study. Am J Respir Crit Care Med 1998; 158: 220-225.

29 Collard HR, King TE Jr, Bartelson BB, Vourlekis JS, Schwarz MI, Brown KK. Changes in clinical and physiologic variables predict survival in idiopathic pulmonary fibrosis. Am J Respir Crit Care Med 2003; 168: 538-542.

30 Flaherty KR, Mumford JA, Murray S, et al. Prognostic implications of physiologic and radiographic changes in idiopathic interstitial pneumonia. Am J Respir Crit Care Med 2003; 168: 543-548.

31 Tzanakis N, Samiou M, Lambiri I, Antoniou K, Siafakas N, Bouros D. Evaluation of health-related quality-of life and dyspnea scales in patients with idiopathic pulmonary fibrosis. Correlation with pulmonary function tests. Eur J Intern Med 2005; 16: 105-112.

32 Gay SE, Kazerooni EA, Toews GB, et al. Idiopathic pulmonary fibrosis: predicting response to therapy and survival. Am J Respir Crit Care Med 1998; 157: 1063-1072.

33 Lynch DA, David Godwin J, Safrin S, et al. High-resolution computed tomography in idiopathic pulmonary fibrosis: diagnosis and prognosis. Am J Respir Crit Care Med 2005; 172: 488-493.

34 Kalra S, Utz JP, Ryu JH. Interferon gamma-1b therapy for advanced idiopathic pulmonary fibrosis. Mayo Clin Proc. 2003; 78: 1082-1087. 
35 Nathan SD, Barnett SD, Moran B, et al. Interferon gamma$1 \mathrm{~b}$ therapy for idiopathic pulmonary fibrosis: an intrapatient analysis. Respiration 2004; 71: 77-82.

36 Prasse A, Muller KM, Kurz C, Hamm H, Virchow JC Jr. Does interferon- $\gamma$ improve pulmonary function in idiopathic pulmonary fibrosis? Eur Respir J 2003; 22: 906-911.

37 Honore I, Nunes H, Groussard O, et al. Acute respiratory failure after interferon- $\gamma$ therapy of end-stage pulmonary fibrosis. Am J Respir Crit Care Med 2003; 167: 953-957.

38 Selman M. A dark side of interferon- $\gamma$ in the treatment of idiopathic pulmonary fibrosis? Am J Respir Crit Care Med 2003; 167: 945-946.

39 Martinez FJ, Safrin S, Weycker D, et al. The clinical course of patients with idiopathic pulmonary fibrosis. Ann Intern Med 2005; 142: 963-967. 